\title{
Clinical Overview of Cancer Patients in Province Two of Nepal: A Single Center Experience
}

\author{
Anshu K Thakur', Anish Shah, Barun K Ray \\ 'Binaytara Foundation Cancer Center, Kadam Chowk, Kapileshwore Marg, Janakpurdham, ${ }^{2 B P}$ Koirala Institute of \\ Health Sciences, Dharan, ${ }^{3}$ Pipra PHC, Mahottari
}

\section{Corresponding author:}

Anshu K Thakur, MBBS, MD (Oncology)

Binaytara Foundation Cancer Center, Kadam Chowk, Kapileshwore Marg, Janakpurdham, Nepal

Email:anshuthakur@binayfoundation.org

\begin{abstract}
\section{Introduction}

The incidence of cancer is rising in Nepal. It is estimated to reach 38.5 per 100,000 for males and 41.5 per 100,000 for females by 2020. The studies to determine the cancer burden in Nepal at provincial level have been insufficient and those that have been done are more inclined to Province 3. With establishment of a dedicated cancer facility in this area, we present an overview of clinical scenario of cancer patients in Province 2.
\end{abstract}

\section{Methods}

We performed a single centered, retrospective review of 118 patients who were registered in Oncology Clinics between May 2019 and February 2020. Demographics, diagnoses and the treatment strategies were obtained from the medical records.

\section{Results}

Median age of presentation for cancer was 55 years (range, 6 to 83 years) with maximum number of patients falling within range of 50-60 years (31.4\%). 71 patients (60.2\%) were female and 47 patients (39.8\%) were male. The common presenting cancers were gastrointestinal (27.1\%), breast (16.9\%), head and neck (15.3), gynecological $(13.6 \%)$, hematological $(11.9 \%)$ and others (15.2\%). Among the gastrointestinal cancers, carcinoma of gallbladder with 15 cases (46.9\%) was the most frequently occurring, followed by colorectal cancer with 6 cases (18.8\%) and esophageal cancer with 4 cases (12.5\%). Among all, 78 patients $(66.1 \%)$ received palliative care only, 25 patients $(21.2 \%)$ received chemotherapy only, 8 patients $(6.8 \%)$ underwent surgery only, 3 patients (2.5\%) underwent surgery and received chemotherapy as well, 2 patients $(1.7 \%)$ received both chemotherapy and palliative care and 2 patients $(1.7 \%)$ were reassured and observed.

\section{Conclusion}

The most common age of presentation for cancer of any type was 50-60 years, with most common cancer being gastrointestinal in origin. Most of the patients received palliative care owing to their advanced stage at presentation.

Keywords: Cancer, clinical overview, palliative care 